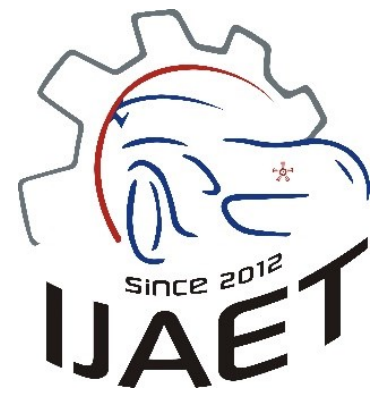

e-ISSN: 2146 - 9067

International Journal of Automotive Engineering and Technologies

journal homepage: http://ijaet.academicpaper.org

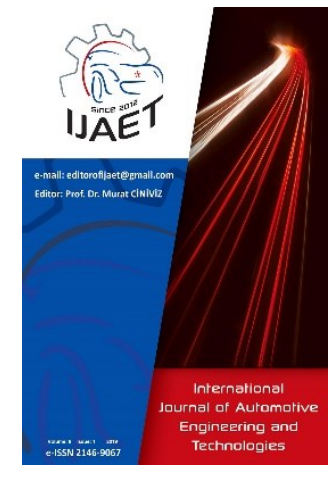

Original Research Article

\title{
Thermodynamic analysis of endoreversible six-stroke Otto cycle with respect to equivalence ratio, residual gas fraction and mean piston speed
}

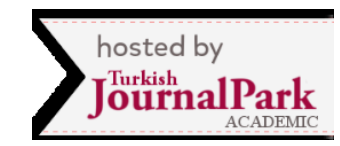

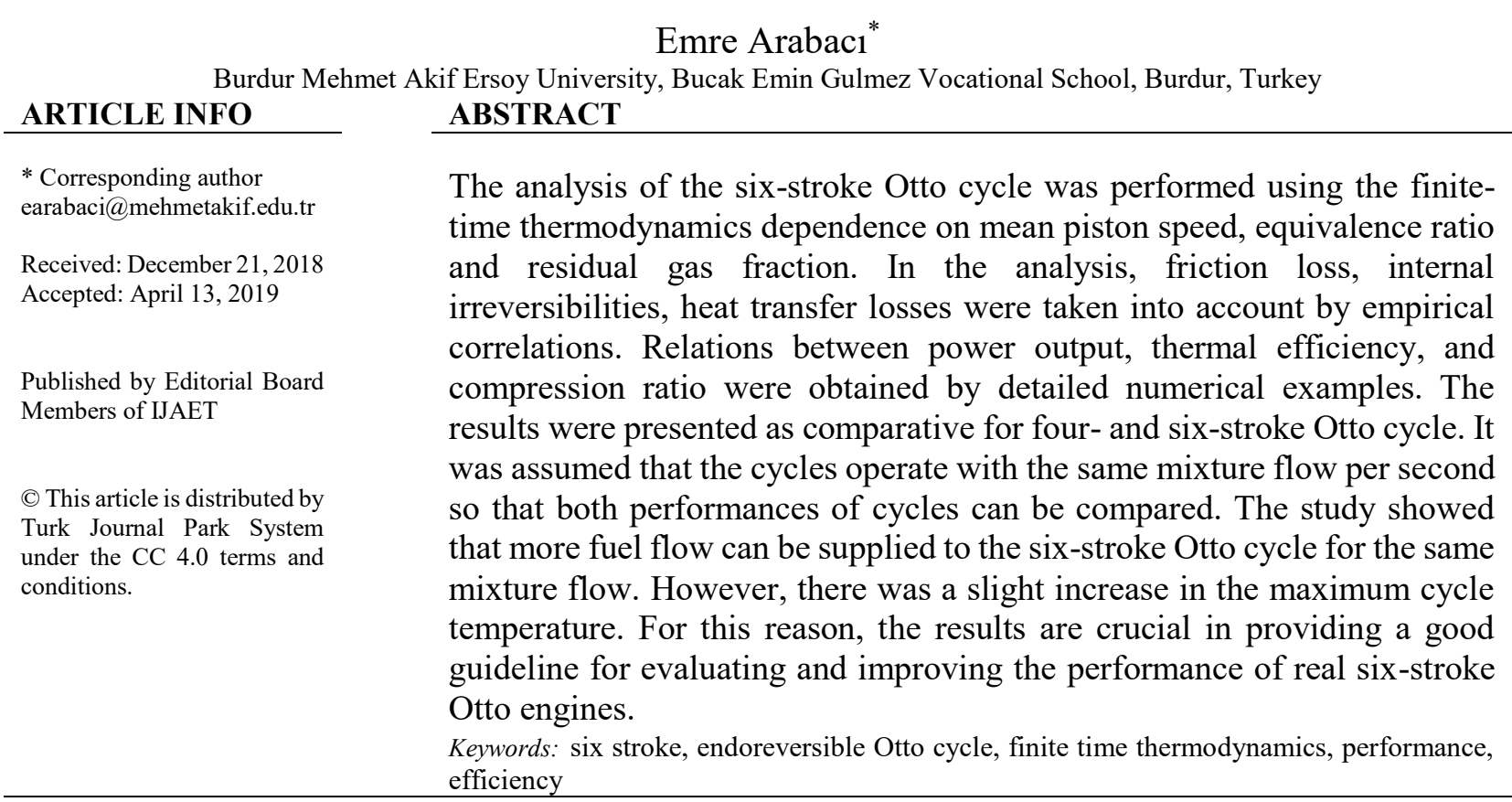

\section{Introduction}

Innovative developments in internal combustion engines are achieved every day. Recently, engine designs are divided into two with a clear line: the high economy and high performance. Particularly in hybrid-electric vehicles, high fuel economy is targeted, so it is desirable that the internal combustion engine is economic, in other words, the thermal efficiency is high [1]. In terms of high thermal efficiency, there are Atkinson and Miller cycles which can be an alternative to conventional Otto cycle. These cycles are usually preferred in hybrid-electric vehicles. Miller and Atkinson cycles are the modified versions of conventional cycles, such as Otto and Diesel cycles. Another modified cycle is the six-stroke cycle, and the invention of this cycle dates back to the 1880s [2]. While sixstroke engines are structurally very similar to four-stroke engines, engine development has always been on four-stroke engines. When the first years of the development of engine technology were examined, the priority was to increase the maximum engine power. Sixstroke engines always keep fuel economy in the forefront. Today, fuel economy is more 
important than engine power. Six-stroke engines are not a forgotten invention, but a potentially pending invention [1-3].

Although the thermal efficiency of six-stroke engines is high, the specific engine volume (displacement volume/power) is also high. A cycle of four-stroke engines is completed on two crankshaft revolutions, while a cycle of six-stroke engines is completed on three crankshaft revolutions [3].

There are many different six-stroke engine designs in the literature [4]. Theoretical and experimental studies on six-stroke engines are generally related to exhaust heat recovery. Exhaust heat recovery is based on the principle of achieving additional work in the cycle by evaporating non-combustible liquids (eg water) in the cylinder using exhaust gases energy [1-4]. Instead of exhaust heat recovery in six-stroke engines, the free-stroke method can also be used to clean the inside of the cylinder and to cool the cylinder volume at the start of the new cycle. Thus, it is envisaged that the volumetric efficiency can be partially increased by internal cooling of the engine [5]. This study is related to the six-stroke engine obtained by adding two free strokes in addition to the four-stroke cycle, and the pressure-crank angle diagram is presented in Figure 1.

In Figure 1 after the exhaust stroke, the free intake stroke (only fresh air) and the free exhaust stroke are realized. At this time, the residual gas fraction in the cylinder is reduced after the exhaust stroke, and the novel cycle is colder and cleaner. Thus, volumetric efficiency and thermal efficiency are increasing.

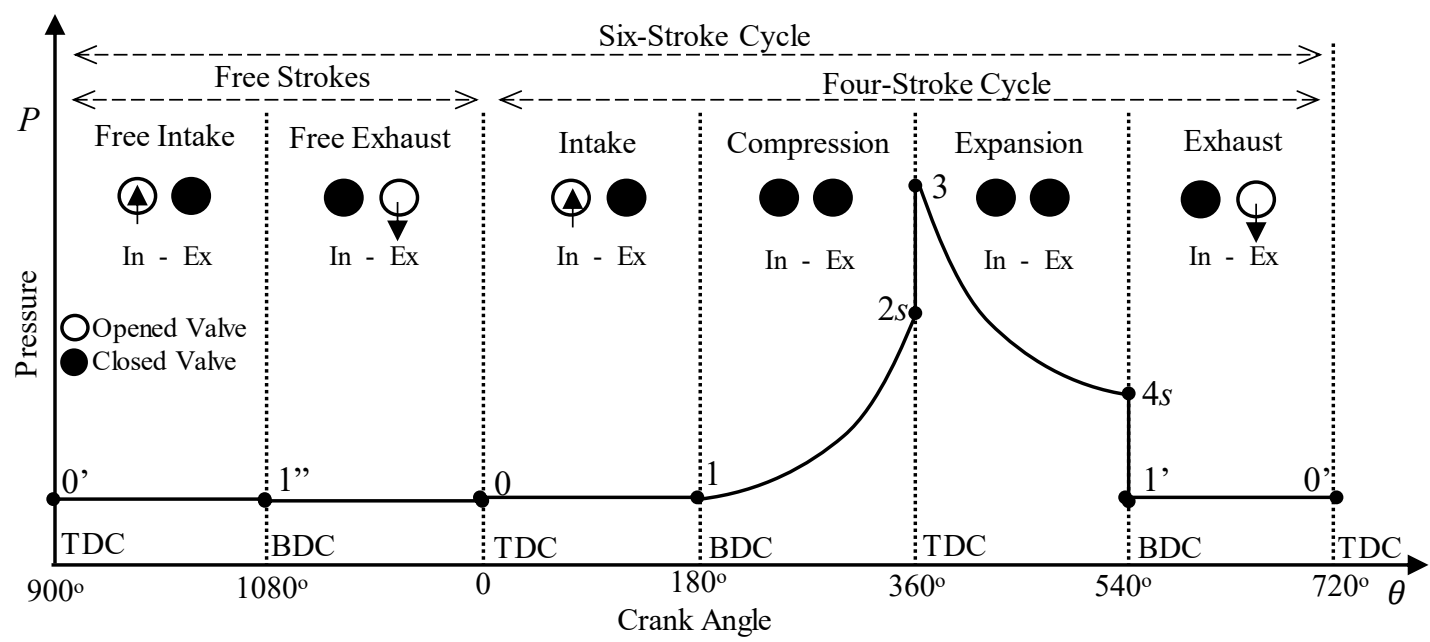

Figure 1. Pressure-crank angle diagram for six-stroke Otto engine cycle

Internal combustion engine cycles are expressed as air standard cycles in classic thermodynamics. In these cycles, friction, combustion, heat transfer, gas exchange, variable specific heats are ignored and ideal cycles occur in infinite time. Because the processes in the infinite time are realized as if they are quasi-static, the work output obtained from the cycle is maximum while the power is equal to zero. For this reason, it is very difficult to simulate the actual engine performance of the ideal cycles with the subject of classical thermodynamics and is not suitable for parametric work [6-8]. The term finite time thermodynamics, first applied by Curzon and Ahlborn in 1975, enables the examination of parameters affecting engine performance such as friction, heat transfer, variable specific heat, volumetric efficiency in ideal cycles, and acknowledges that the cycle has been completed in a certain time. Thus, ideal cycles are practically approximated to the actual engine cycle [7-10]. In the finite time thermodynamics, the cycles are internal-reversible and expressed as endoreversible [10]. Finite time thermodynamics is often one of the preferred practical approaches in real engine cycle analysis. [11]. This approach is used for comparison purposes to demonstrate the effects of variable engine parameters such as mean piston speed, cylinder diameter, cylinder wall temperature, equivalence ratio, stroke length, 
working fluid properties [12]. In the literature, it is possible to come across a number of studies using the finite time thermodynamic approach in examining the performances of real engine cycles. In these studies, it is possible to adopt ideal air [13], fuel-air mixture [14] or fuel-airresidual gas mixture [15] as working fluid as the actual engine cycle model. However, in finite time thermodynamic models, specific heat can be regarded as constant [16] regardless of the temperature, or it can be regarded as a function of temperature [17]. However, different specific heat models [18] for the working fluid can also be compared. The finite time thermodynamics can also be used to compare different characteristic cycles such as Otto-Diesel [19], Otto-Dual-Diesel [20], Otto-Miller [21] and Dual-Dual Atkinson [18]. For actual engines, finite time thermodynamics can be used for the effects on the engine performance of the parameters related to the subjects such as variable compression ratio [11], late intake valve closing method [22], turbocharger [23], alternative fuel mixture [24], steam injection method [25] and gas exchange process [26].

In this study, the effects of the variation of the equivalence ratio, the residual gas fraction and the mean piston speed parameters on the sixstroke Otto cycle engine performance, especially in the case of high thermal efficiency, are investigated by using the finite time thermodynamic approach. The initial cycle temperature is defined as a function of the residual gas fraction, while the specific heat and cylinder wall temperature are considered constant. In addition, the performance of fourand six-stroke Otto cycle has been examined in detail with the numerical example.

\section{Thermodynamic Analysis}

The pressure-volume $(P-v)$ and the temperatureentropy $(T-s)$ diagrams of an endoreversible sixstroke Otto engine cycle is shown in figure 2, where the "s" subscripts denote reversible processes for compression $(1 \rightarrow 2 \mathrm{~s})$ and expansion $(3 \rightarrow 4 s)$. The heat addition $(2 \rightarrow 3)$ and the heat rejection $(4 \rightarrow 1)$ processes are isochoric processes [15]. The process $4 \rightarrow 1$ shown in the $T$-s diagram for the six-stroke Otto engine cycle actually takes place as $4 \rightarrow 1^{\prime} \rightarrow 00^{\prime} \rightarrow 1$ ' $\rightarrow 0 \rightarrow 1$. However, this process is modeled as $4 \rightarrow 1$ to simulate the cycle model to the Otto engine cycle. In the figure 2 , the $0 \rightarrow 1$ and $1^{\prime} \rightarrow 0^{\prime} \rightarrow 1 " \rightarrow 0$ processes shown in the $P-v$ diagram are the gas change processes for the sixstroke Otto engine cycle.
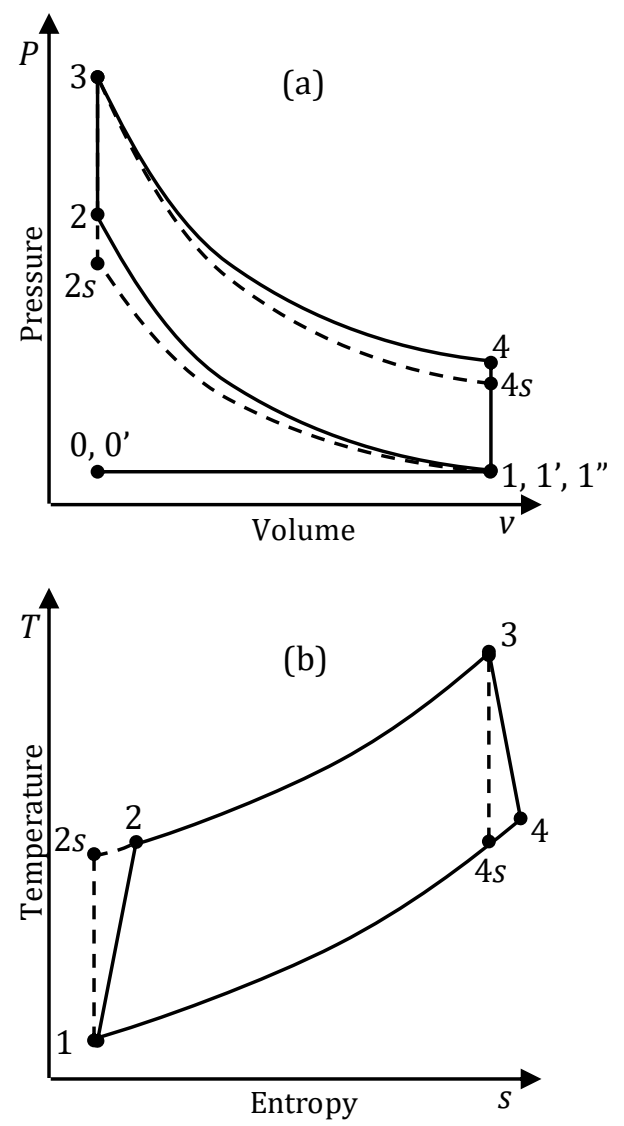

Figure 2. Six-stroke Otto engine cycle (a) $P-v$ diagram, (b) $T$-s diagram

The six-stroke Otto engine cycle is a modified version of the four-stroke Otto engine cycle, and for this reason, firstly equations have been presented for the four-stroke Otto engine cycle and finally the modifications required for the six-stroke Otto engine cycle have been explained [1].

The relations between the fuel flow $\left(\dot{m}_{f}\right)$ and mean piston speed $\left(\bar{S}_{p}\right)$ [6-8], between $\dot{m}_{f}$ and the fuel-air-residual gas (mixture) flow $\left(\dot{m}_{t}\right)$ [68] are defined as:

$\dot{m}_{f}=0.0003 \bar{S}_{p}$

$\dot{m}_{t}=\dot{m}_{f}+\dot{m}_{a}+\dot{m}_{r}$

$\dot{m}_{t}=\frac{\dot{m}_{f}\left(\phi+x_{A F s}\right)}{\phi\left(1-x_{r}\right)}$

where $x_{A F S}$ is the air-fuel ratio for stoichiometric conditions, $\dot{m}_{a}$ is air flow, $\phi$ is equivalance ratio and $x_{r}$, is the residual gas fraction from previous cycle, and one can find it as [6-8]:

$x_{r}=\dot{m}_{r} / \dot{m}_{t}$ 
where $\dot{m}_{r}$ is residual gases flow. It should be noted here that the residual gases were assumed to consist of $\mathrm{CO}_{2}, \mathrm{H}_{2} \mathrm{O}$ and $\mathrm{N}_{2}$.

The specific heat at constant volume $\left(c_{v t}\right)$ and the gas constant $\left(R_{t}\right)$ for the working fluid are defined as:

$$
\begin{aligned}
& c_{v t}=\frac{\left\{\begin{array}{c}
\left(1-x_{r}\right)\left(x_{A F s} c_{v a}+\phi c_{v f}\right) \\
+x_{r}\left(\phi+x_{A F s}\right) c_{v r}
\end{array}\right\}}{\left(\phi+x_{A F s}\right)} \\
& R_{t}=\frac{\left\{\begin{array}{c}
\left(1-x_{r}\right)\left(x_{A F s} R_{a}+\phi R_{f}\right) \\
+x_{r}\left(\phi+x_{A F s}\right) R_{r}
\end{array}\right\}}{\left(\phi+x_{A F s}\right)}
\end{aligned}
$$

where $c_{v a}, c_{v f}$ and $c_{v r}$ are the mass specific heat at constant volume for air, fuel and residual gases, and $R_{a} R_{f}$, and $R_{r}$ are the gas constant for air, fuel and residual gases, respectively.

For the two adiabatic processes, the compression and expansion efficiencies [14, $15]$.

$\eta_{c}=\left(T_{2 s}-T_{1}\right) /\left(T_{2}-T_{1}\right)$

$\eta_{e}=\left(T_{4}-T_{3}\right) /\left(T_{4 s}-T_{3}\right)$

These two efficiencies are used to describe the internal irreversibility of the processes. The equations for reversible adiabatic processes $1 \rightarrow 2$ s and $3 \rightarrow 4$ s are as follows [27]:

$c_{v t} \ln \left(T_{2 s} / T_{1}\right)=R_{t} \ln (\varepsilon)$

$c_{v t} \ln \left(T_{4 s} / T_{3}\right)=-R_{t} \ln (\varepsilon)$

The added heat flow per second in the isochoric $(2 \rightarrow 3)$ heat addition process may be written as [28]:

$\dot{Q}_{\text {in }}=\dot{m}_{t} c_{v t}\left(T_{3}-T_{2}\right)=$

$\frac{\dot{m}_{f}}{\phi}\left\{\begin{array}{c}\left(x_{A F s} c_{v a}+\phi c_{v f}\right) \\ +\left[\frac{x_{r} c_{v r}\left(\phi+x_{A F s}\right)}{\left(1-x_{r}\right)}\right]\end{array}\right\}\left(T_{3}-T_{2}\right)$

The rejected heat flow per second in the isochoric $(4 \rightarrow 1)$ heat rejection process may be written as [28]:

$\dot{Q}_{\text {out }}=\dot{m}_{t} c_{v t}\left(T_{4}-T_{1}\right)=$

$\frac{\dot{m}_{f}}{\phi}\left\{\begin{array}{l}\left(x_{A F s} c_{v a}+\phi c_{v f}\right) \\ +\left[\frac{x_{r} c_{v r}\left(\phi+x_{A F s}\right)}{\left(1-x_{r}\right)}\right]\end{array}\right\}\left(T_{4}-T_{1}\right)$

The total energy flow of the fuel may be written as [6-8]:

$\dot{Q}_{f}=\eta_{c o m} \dot{m}_{f} H_{u}=\left(-1.4474+\frac{4.1858}{\phi}-\frac{1.8671}{\phi^{2}}\right) \dot{m}_{f} H_{u}$

where $\eta_{\text {com }}$ and $H_{u}$ are the combustion efficiency and lower heat value of the fuel, respectively. Heat transfer losses for an ideal Otto cycle model can be negligible, but for a real Otto cycle, the heat transfer irreversibility between the working fluid and the cylinder wall is so important that it cannot be negligible. The heat loss on the cylinder wall can be expressed by a simple linear equation.

$\dot{Q}_{h t}=\frac{\dot{m}_{f} \beta\left(\phi+x_{A F s}\right)}{\phi}\left(T_{2}+T_{3}-2 T_{w}\right)$

where $\beta$ is the heat leakage coefficient of the cylinder wall. The relationship between $\dot{Q}_{f}, \dot{Q}_{i n}$ and $\dot{Q}_{h t}$ can be defined as follows [6-8]:

$\dot{Q}_{\text {in }}=\dot{Q}_{f}-\dot{Q}_{h t}$

In thermodynamic analyzes $T_{1}$ is considered a constant value as the initial cycle temperature. It is generally accepted that $T_{0}$ and $T_{1}$ are equal. The $T_{1}$ is defined as a specific function because the residual gas fraction is now included in the calculation. It is assumed that $T_{1}$ changes according to reference temperature $\left(T_{0}\right), T_{4}$ and $x_{r} . T_{1}$ can be written as [6-8]:

$T_{1}=T_{0}+\frac{x_{r} R_{r}\left(T_{4}-T_{0}\right)}{R}$

The friction loss can be expressed as a function of $\bar{S}_{p}[14]$ :

$\left|P_{\mu}\right|=\mu\left(\bar{S}_{p}\right)^{2}$

where $\mu$ is the coefficient of friction, which takes into account the global losses. The power output of the Otto cycle engine is expressed by:

$$
\begin{aligned}
& P=\dot{Q}_{\text {in }}-\dot{Q}_{\text {out }}-\left|P_{\mu}\right| \\
& =\frac{\dot{m}_{f}}{\phi R_{t}}\left\{\begin{array}{l}
\left(x_{A F S} c_{v a}+\phi c_{v f}\right) \\
+\left[\frac{x_{r} c_{v r}\left(\phi+x_{A F s}\right)}{\left(1-x_{r}\right)}\right]
\end{array}\right\}\left\{\begin{array}{c}
R_{t}\left(T_{3}-T_{2}\right) \\
+\left(R_{t}+x_{r} R_{r}\right)\left(T_{4}-T_{0}\right)
\end{array}\right\}- \\
& \mu\left(\bar{S}_{p}\right)^{2}
\end{aligned}
$$

The efficiency of the cycle is expressed by [14]:

$\eta_{t h}=P / \dot{Q}_{\text {in }}$

When $\bar{S}_{p}, c_{v a}, c_{v f}, c_{v r}, R_{a}, R_{f}, R_{r}, \beta, T_{w}, T_{0}, \mu, x_{r}$, $x_{A F S}$ and $\phi$ are given, $T_{1}, T_{2}, T_{2 s}, T_{3}, T_{4}$, and $T_{4 s}$ can be obtained from Eqs. (7-16). Using Eq. 18 and Eq. 19, power output and thermal efficiency can be determined, respectively.

The above equations apply to the four-stroke Otto cycle. Some variables must be redefined so that these equations can be used for the sixstroke Otto cycle. 
At the same engine speed, the number of cycles involved in the four-stroke engine and the sixstroke engine are different. In four-stroke engines, one cycle is completed in two revolutions while in six-stroke engines, one cycle is completed in three revolutions. This results in lower fuel consumption for the sixstroke engine for the same engine volume, in other words, lower heat input and lower power output. The same mixture flow $\left(\dot{m}_{t}=\dot{m}_{t 6}\right)$ conditions have been taken into account for the comparison of the four-stroke engines and the six-stroke engines.

In order to use the equations described for the above four-stroke Otto cycle for the six-stroke Otto cycle it is sufficient to redefine the variables $x_{r}$ and $\dot{m}_{f}$.

$x_{r 6}=\frac{x_{r}}{\varepsilon+1}$

$\dot{m}_{f 6}=\frac{\dot{m}_{f}\left(1-x_{r 6}\right)}{\left(1-x_{r}\right)}=\frac{\dot{m}_{f}\left(\varepsilon-x_{r}+1\right)}{\left(1-x_{r}\right)(\varepsilon+1)}$

where $x_{r 6}$ is the residual gas fraction for sixstroke Otto cycle and $\dot{m}_{f 6}$ is the fuel flow. In the above equations, $x_{r 6}$ and $\dot{m}_{f 6}$ should be used instead $x_{r}$ and $\dot{m}_{f}$, respectively.

\section{Results and Discussion}

The following constants and parameters are used for the numerical example: $\eta_{c}=0.97, \eta_{e}=$ $0.97, x_{A F S}=15.05, T_{0}=300 \mathrm{~K}, \beta=0.5 \mathrm{~kJ} / \mathrm{kgK}, \mu=$ $12.9 \mathrm{Ns} / \mathrm{m}, \quad H_{u}=44790 \mathrm{~kJ} / \mathrm{kg}, \quad c_{v a}=0.718 \mathrm{~kJ} / \mathrm{kgK}$, $c_{v f}=1.638 \mathrm{~kJ} / \mathrm{kgK}, \quad c_{v r}=0.866 \mathrm{~kJ} / \mathrm{kgK}, \quad R_{a}=$ $0.287 \mathrm{~kJ} / \mathrm{kgK}, R_{f}=0.073 \mathrm{~kJ} / \mathrm{kgK}, R_{r}=0.307 \mathrm{~kJ} / \mathrm{kgK}$, $T_{w}=400 \mathrm{~K}, \phi=0.85 \rightarrow 1.15, x_{r}=5 \% \rightarrow 20 \%, \varepsilon=$ $2 \rightarrow 100, \bar{S}_{p}=7 \rightarrow 15 \mathrm{~m} / \mathrm{s}, \dot{m}_{t}=\dot{m}_{t 6}$ [5-28]. It is assumed that the fuel is used as a gasoline equivalent of isooctane $\left(\mathrm{C}_{8} \mathrm{H}_{18}\right)$. This study focuses on the investigation of the effects of mean piston speed and equivalence ratio and residual gas fraction on performance of fourand six-stroke Otto cycle engine. The performance parameters obtained for both engines are compared.

The variation of $\dot{m}_{f}$ versus $\varepsilon$ for a constant $\bar{S}_{p}$ is shown in Figure 3, since $\dot{m}_{t}$ values for four- and six-stroke engines are assumed to be equal in this study. It is found that $\dot{m}_{f 6}$ increases with the increase of $x_{r}$. While the $\dot{m}_{t}$ parameter changes as a function of $\bar{S}_{p}, \phi, x_{A F s}$ and $x_{r}$, the $\dot{m}_{f}$ parameter changes only as a function of the
$\bar{S}_{p}$. The $\dot{m}_{f 6}$ parameter, however, changes as a function of $\dot{m}_{f}, \varepsilon$ and $x_{r}$. Because $\dot{m}_{t}=\dot{m}_{t 6}$ is assumed in this study, the $\dot{m}_{f 6}$ parameter of the four-stroke engine does not change according to the $x_{r}$, while the $\dot{m}_{f 6}$ parameter of the six-stroke engine increases with the $x_{r}$.

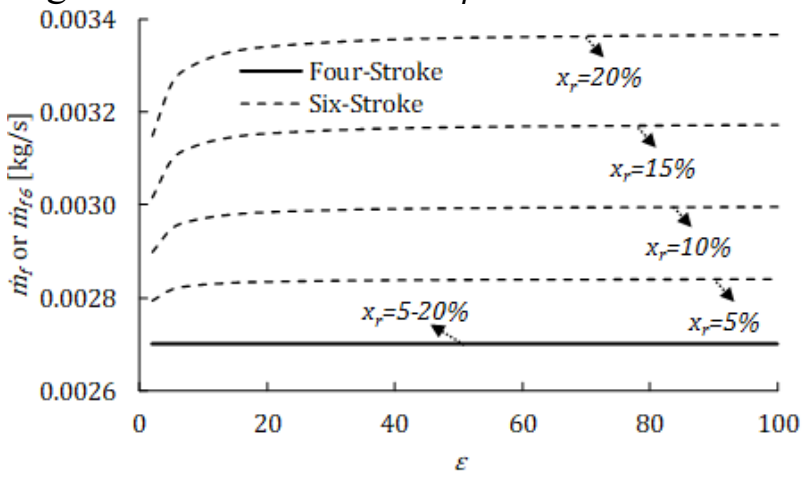

Figure 3. The fuel consumption versus compression ratio $\left(\Phi=1.00\right.$ and $\left.\bar{S}_{p}=9 \mathrm{~m} / \mathrm{s}\right)$

The variations in the temperatures $T_{1}, T_{2}, T_{3}$ and $\mathrm{T}_{4}$ with the compression ratio are shown in Figure 4 It is found that $T_{1}$ and $T_{4}$ decreases with the increase of compression ratio, while $T_{2}$ and $T_{2}$ increase with the increase of compression ratio. It is seen that $T_{1}$, which is the initial cycle temperature, is lower in the six-stroke Otto cycle than in the four-cycle Otto cycle. This means that the cooling load for an engine is decreasing.

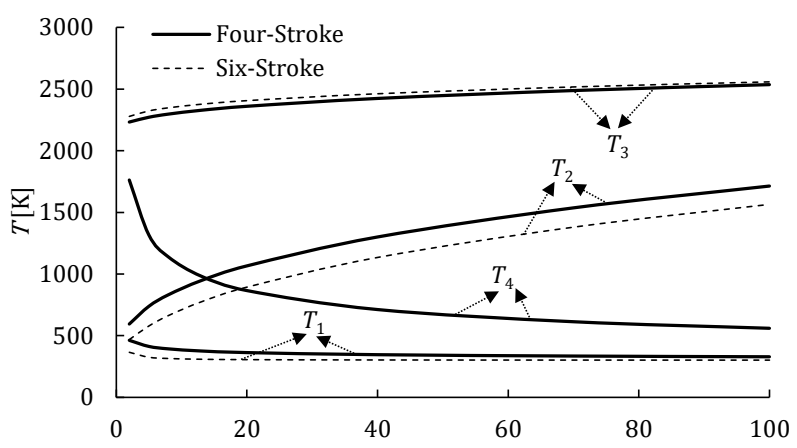

Figure 4. The temperature versus compression ratio $\left(x_{r}=10 \%, \Phi=1.00\right.$ and $\left.\bar{S}_{p}=9 \mathrm{~m} / \mathrm{s}\right)$

The equations presented above regarding the power output and thermal efficiency of the fourand six-stroke Otto cycle are generally based on the equivalence ratio, the mean piston speed and the residual gas fraction. The graphs shown in figures 5-10 expressing power outputcompression ratio and power output-thermal efficiency relations were obtained so that the effects of these parameters on both cycles can be examined. An increase in the compression ratio leads to an increase in the power output at first, and after reaching a peak, the power output 
appears to decrease significantly with increasing compression ratio. The equivalence ratio, mean piston speed and residual gas fraction were found to play an important role in cycle performance. It is evident from these figures that the equivalence ratio, the mean piston speed, and the effect on the power output over the residual gas fraction are related to the compression ratio.

Figure 5 and 6 show the effect of the change in the equivalence ratio on the output power.

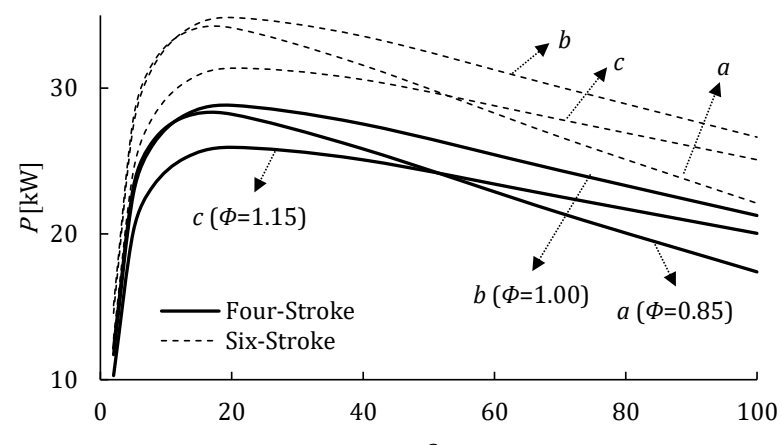

Figure 5. Effect of equivalence ratio on the variation of the power output with compression ratio $\left(x_{r}=10 \%\right.$ and $\left.\bar{S}_{p}=9 \mathrm{~m} / \mathrm{s}\right)$

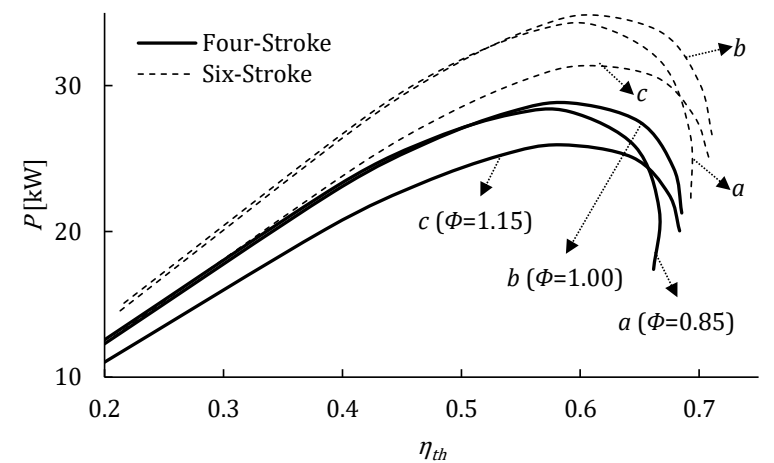

Figure 6. Effect of equivalence ratio on the variation of the power output with thermal efficiency $\left(x_{r}=10 \%\right.$ and $\bar{S}_{p}=9 \mathrm{~m} / \mathrm{s}$ )

Figure 5 shows that as the mixture is enriched at low compression ratios, the output power decreases, and at very high compression ratios, the output power decreases as the stoichiometric ratio increases. This is the same for both cycles. However, the output power is also higher due to the compression ratio, since the constant mean piston speed and the residual gas fraction have higher heat input. When Figure 6 is examined, it is seen that the six-stroke engine has higher thermal efficiency than the four-stroke engine. It can be seen that the power output tendency depending on the equivalence ratio for both cycles is the same, but the six-stroke engine cycle can operate at higher thermal efficiencies.
Figure 7 and figure 8 show the effect of the change of the residual gas fraction on the output power.

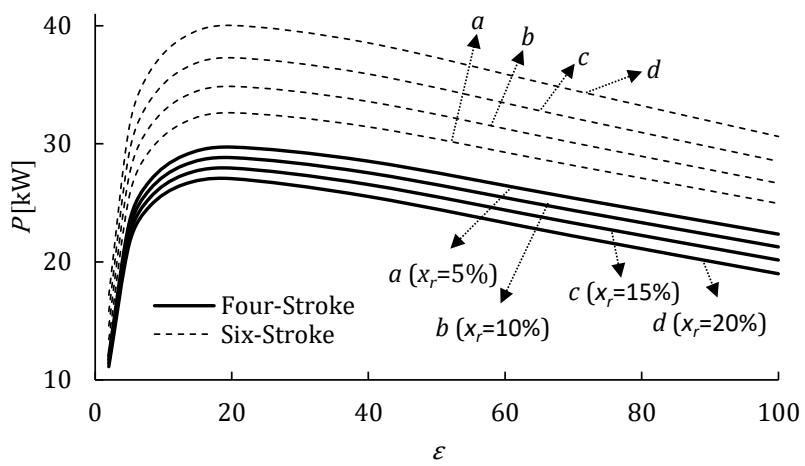

Figure 7. Effect of residual gas fraction on the variation of the power output with compression ratio $(\Phi=1.00$ and $\bar{S}_{p}=9 \mathrm{~m} / \mathrm{s}$ )

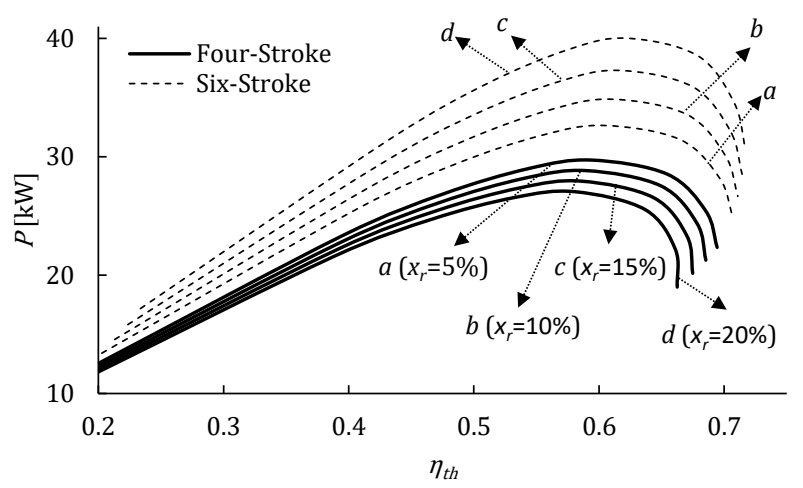

Figure 8. Effect of residual gas fraction on the variation of the power output with thermal efficiency $(\Phi=1.00$ and $\bar{S}_{p}=9 \mathrm{~m} / \mathrm{s}$ )

Figure 7 shows that as the residual gas fraction increases, the power output decreases in the four-stroke engine and increases in the sixstroke engine. The main reason for this is the increase in the $\dot{m}_{f}$ depending on the residual gas fraction (see Figure 3). In Figure 8, the thermal efficiency of the four-stroke engine decreases with the increase of the residual gas fraction. In the six-stroke engine, the increase in residual gas fraction increases thermal efficiency.

Figure 9 and Figure 10 show the effect of mean piston speed change on the output power. Fuel flow was defined as a parameter of mean piston speed (equation 1). When Figure 9 is examined, the output power increases due to the constant equivalence ratio and the increase of the mean piston speed for the residual gas fraction, as well as the fuel flow for any compression ratio. When Figure 10 is examined, the maximum efficiency decreases as the mean piston speed increases. It is also seen that the six-stroke engine has reached higher efficiency values. 


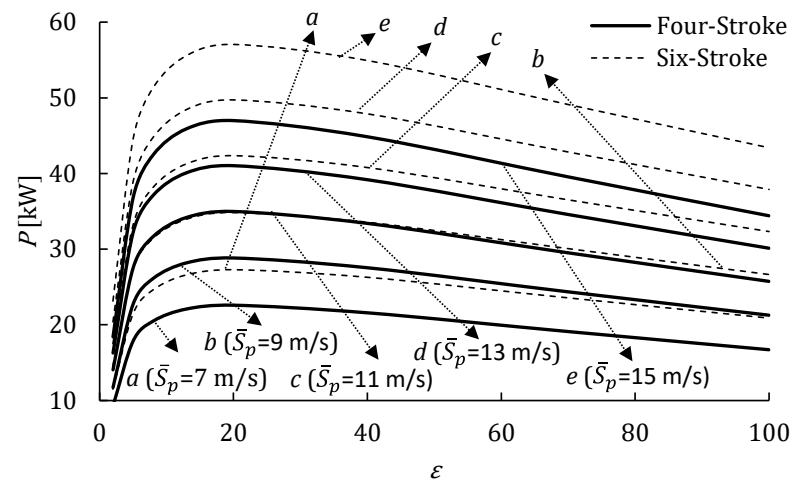

Figure 9. Effect of mean piston speed on the variation of the power output with compression ratio $\left(x_{r}=10 \%\right.$ and $\Phi=1.00)$

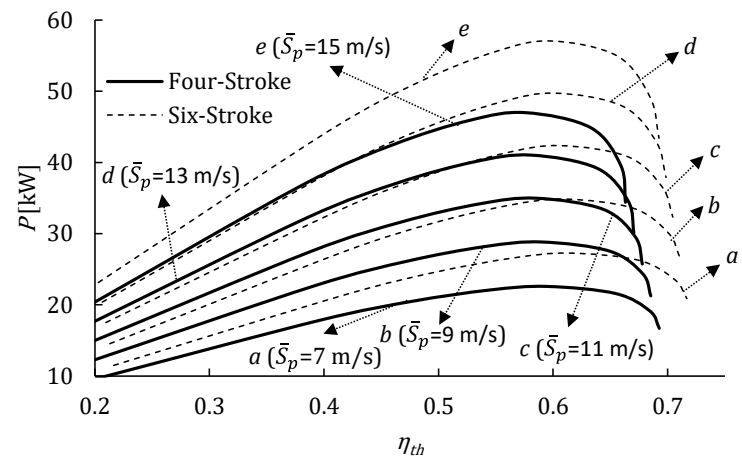

Figure 10 Effect of mean piston speed on the variation of the power output with thermal efficiency $\left(x_{r}=10 \%\right.$ and $\Phi=1.00)$

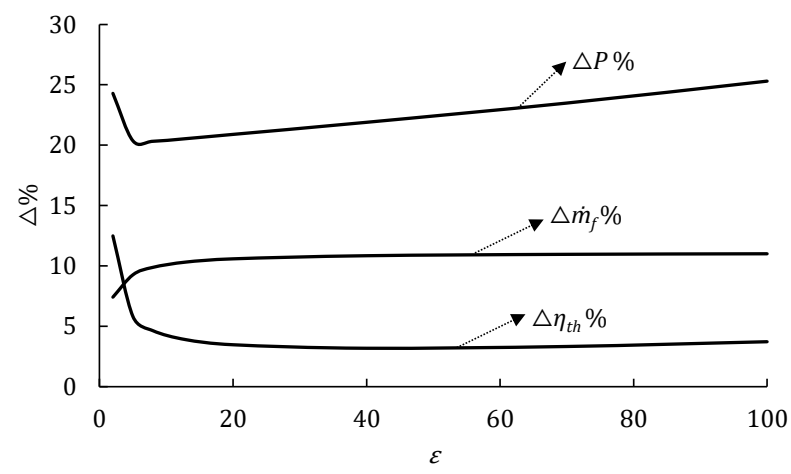

Figure 11. The change of the performance parameters versus compression ratio $\left(x_{r}=10 \%, \bar{S}_{p}=9 \mathrm{~m} / \mathrm{s}\right.$ and

$$
\Phi=1.00)
$$

As a general evaluation, the $\dot{m}_{f}$ value for the same $\dot{m}_{t}$ value is higher than that of the sixstroke engine. However, for the same conditions, the thermal efficiency of the sixstroke engine is higher than the four-stroke engine. Because both $\dot{m}_{f}$ and $\eta_{t h}$ are high, the output power of the six-stroke engine is quite high compared to the four-stroke engine. Figure 11 shows the performance parameters of the four- and six-stroke engines for the same $x_{r}, \Phi$ and $\bar{S}_{p}$ values, depending on the compression ratio. For the same conditions, the $\dot{m}_{f}$ is about $10 \%$ higher than the four-stroke engine, while the $\eta_{t h}$ is about $5 \%$ higher, with the result that the output power of the six-stroke engine is about 20\% higher than the four-stroke engine.

\section{Conclusions}

In this study, the effects of the residual gas fraction, mean piston speed, and equivalence ratio on the performance of a six-stroke Otto cycle were investigated. Since the six-cycle engine concept is an unconventional concept, conventional 4-stroke Otto cycle results were obtained and compared for the same conditions so that the results obtained can be interpreted. In the study carried out, the mixture flow was assumed to be the same in both cycles. It was assumed, however, that the initial cycle temperature is a function of the residual gas fraction.

The model presented in this study was created to show only the tendency of the motor performance not to change according to certain parameters. Although the results obtained here are notoriously impressive for engine designers, it is never enough for a real engine design. Furthermore, the results obtained here do not show that a real engine will operate at this performance. Although the suction and exhaust processes are very important in the six-stroke engine concept, the mechanical design and performance of the valve mechanism has been intentionally ignored.

The general conclusions from the results of this study are as follows:

- The performance trend of the six-stroke Otto cycle due to the compression ratio is quite similar to the four-stroke Otto cycle.

- Both cycles have the same residual gas fraction, but the actual residual gas fraction for six-stroke Otto cycle as a function of the compression ratio due to the effect of free strokes in the six-stroke Otto cycle is much less. However, since the engine does not produce any work during free strokes, the initial cycle temperature is relatively low. This means that the engine is cooling itself a little. In other words, the cooling load of the engine is reduced. This is an important advantage of the six-stroke Otto engine cycle.

- Compared to the four- and six-stroke Otto engines operating under the same conditions with equivalent physical 
characteristics, the four-stroke Otto engine provides higher output power than the sixstroke Otto engine. In contrast to this, the sixstroke engine has a higher thermal efficiency than the four-stroke engine. The main reason why the thermal efficiency is high despite the low output power is that the cycle duration are different at the same engine speed. The mixture flow was considered to be the same for comparison between two cycles. In this case, fuel flow can be achieved for the same amount of mixture for the six-stroke Otto engine.

The analysis helped to understand the strong effects of the residual gas fraction, mean piston speed, and equivalence ratio on the performance of a six-stroke Otto cycle. For this reason, the results are crucial in providing a good guide for performance evaluation and improvement of real six-stroke Otto engines.

\section{Nomenclature}

$c_{v a} \quad[\mathrm{~kJ} / \mathrm{kgK}]$

$c_{v f} \quad[\mathrm{~kJ} / \mathrm{kgK}]$

$c_{v r} \quad[\mathrm{~kJ} / \mathrm{kgK}]$

$c_{v t} \quad[\mathrm{~kJ} / \mathrm{kgK}]$

$H_{u} \quad[\mathrm{~kJ} / \mathrm{kg}]$

$\dot{m}_{a} \quad[\mathrm{~kg} / \mathrm{s}]$

$\dot{m}_{f} \quad[\mathrm{~kg} / \mathrm{s}]$

$\dot{m}_{f 6} \quad[\mathrm{~kg} / \mathrm{s}]$

$\dot{m}_{r} \quad[\mathrm{~kg} / \mathrm{s}]$

$\dot{m}_{t} \quad[\mathrm{~kg} / \mathrm{s}]$

$P \quad[\mathrm{~kW}]$

$P_{\mu} \quad[\mathrm{kW}]$

$\dot{Q}_{h t} \quad[\mathrm{~kJ} / \mathrm{s}]$

$\dot{Q}_{f} \quad[\mathrm{~kJ} / \mathrm{s}]$

$\dot{Q}_{\text {in }} \quad[\mathrm{kJ} / \mathrm{s}]$

$\dot{Q}_{\text {out }} \quad[\mathrm{kJ} / \mathrm{s}]$

$R_{a} \quad[\mathrm{~kJ} / \mathrm{kgK}]$

$R_{f} \quad[\mathrm{~kJ} / \mathrm{kgK}]$

$R_{r} \quad[\mathrm{~kJ} / \mathrm{kgK}]$

$R_{t} \quad[\mathrm{~kJ} / \mathrm{kgK}]$

$\bar{S}_{p} \quad[\mathrm{~m} / \mathrm{s}]$

$T_{0} \quad[\mathrm{~kJ} / \mathrm{kgK}]$

$\begin{array}{ll}T_{w} & {[\mathrm{~kJ} / \mathrm{kgK}]}\end{array}$

$x_{A F S} \quad[-]$

$x_{r} \quad[-]$

$x_{r 6} \quad[-]$

stroke

$W_{\text {cnet }}[\mathrm{kJ}]$

$\eta_{c} \quad[-]$

$\eta_{\text {com }} \quad[-]$

$\begin{array}{ll}\eta_{e} & {[-]} \\ \eta_{t h} & {[-]} \\ \Phi & {[-]} \\ \beta & {[\mathrm{kJ} / \mathrm{kgK}]} \\ \varepsilon & {[-]} \\ \mu & {[\mathrm{Ns} / \mathrm{m}]} \\ \tau_{c} & {[\mathrm{~s}]}\end{array}$

expansion efficiency thermal efficiency equivalence ratio heat leakage coefficient compression ratio coefficient of friction period of cycle

\section{References}

1. E. Arabaci, and Y. İçingür, "Thermodynamic investigation of experimental performance parameters of a water injection with exhaust heat recovery six-stroke engine" Journal of the Energy Institute, 2016, 89, 569577, DOI:10.1016/j.joei.2015.06.006.

2. E. Arabaci, Y. İçingür, H. Solmaz, A. Uyumaz, and E. Yilmaz, "Experimental investigation of the effects of direct water injection parameters on engine performance in a six-stroke engine". Energy conversion and management, 2015, 98, 89-97, DOI:10.1016/j.enconman.2015.03.045.

3. Y. İçingür, E. Arabaci, "Performance and 1dealized air-fuel cycle analysis of a sixstroke spark-ignition engine". Journal of Polytechnic, 2013, 16, 37-44, DOI: $10.2339 / 2012.16 .1$

4. E. Arabaci, "Six-stroke reciprocating internal combustion engines" Mehmet Akif Ersoy University Journal of Natural and Applied Sciences Institute, 2012, 3, 37-45.

5. H. Kelem and E. Kelem, E, U.S. Patent No. 7,726,268. Washington, DC: U.S. Patent and Trademark Office, 2010.

6. Özdemir, B. Kiliç, E. Arabacı, R. Orman. "Effect of mean piston speed and residual gas fraction on performance of a fourstroke irreversible Otto cycle engine". Scientific Journal of Mehmet Akif Ersoy University, 2018, 1, 6-12.

7. E. Arabac1, "Artık gaz kesri ve kurs oranının tersinmez Otto çevriminin performansina ve entropi üretimine etkileri" Avrupa Bilim ve Teknoloji Dergisi, 2018, 14, 83-89. DOI: 10.31590/ejosat.481881

8. E. Arabacı, E, B. Kılıç," Kurs Oranı Ve Artık Gaz Kesrinin Otto Cevrimli Bir Motorun Performansina Etkisi" Mehmet Akif Ersoy Üniversitesi Uygulamalı Bilimler Dergisi, 2018, 2, 100-111. DOI: 10.31200/makuubd.447745

9. F.L. Curzon, B. Ahlborn "Efficiency of a Carnot engine at maximum power output" 
American Journal of Physics, 1975, 43, 22-24.

10. S.C. Kaushik, S.K. Tyagi, P. Kumar, "Finite time thermodynamics of power and refrigeration cycles". Springer International Publishing 2017.

11. R. Ebrahimi, M. Hoseinpour, "Performance analysis of irreversible Miller cycle under variable compression ratio" Journal of Thermophysics and Heat Transfer, 2013, 27, 542-548, DOI:10.2514/1. T3981.

12. S.A. Klein, "An explanation for observed compression ratios in internal combustion engines" Journal of engineering for gas turbines and power, 1991, 113, 511-513, DOI:10.1115/1.2906270.

13. Y.L. Ge, L. Chen, and F.R. Sun, "Ecological Optimization of an Irreversible Otto Cycle with Variable Specific Heats of Working Fluid" Proceedings of the Chinese Society of Engineering Thermophysics on Engineering Thermophysics and Energy Utility, Wuhan, China, 2011, 5-7, DOI: 10.1615/TFEC2017.fna.018308.

14. R. Ebrahimi, "Effects of mean piston speed, equivalence ratio and cylinder wall temperature on performance of an Atkinson engine" Mathematical and Computer Modelling, 2011, 53, 1289-1297, DOI:10.1016/j.mcm.2010.12.015.

15. R. Ebrahimi, "Thermodynamic Modeling of an Atkinson Cycle with respect to Relative Air-Fuel Ratio, Fuel Mass Flow Rate and Residual Gases" Acta Physica Polonica, A., 2013, 124,

29-34,

DOI:10.12693/APhysPolA.124.29.

16. R. Ebrahimi, "Effect of Volume Ratio of Heat Rejection Process on Performance of an Atkinson Cycle" Acta Physica Polonica A, 2018, 201-205, DOI:10.12693/APhysPolA.133.201.

17. J. You, L. Chen, Z. Wu, and F. Sun," Thermodynamic performance of Dual-Miller cycle (DMC) with polytropic processes based on power output, thermal efficiency and ecological function" Science China Technological Sciences, 2018, 61, 453-463, DOI:10.1007/s11431-017-9108-2.

18. Y. Ge, L. Chen, F. Sun, and C. Wu, "Thermodynamic simulation of performance of an Otto cycle with heat transfer and variable specific heats of working fluid" International Journal of Thermal Sciences, 2005, 44, 506-511,
DOI:10.1016/j.ijthermalsci.2004.10.00.

19. G. Gonca, "Comparative performance analyses of irreversible OMCE (Otto Miller cycle engine)-DiMCE (Diesel miller cycle engine)-DMCE (Dual Miller cycle engine)" Energy, 2016, 109, 152-159, DOI:10.1016/j.energy.2016.04.049.

20. Y. Zhao, and J. Chen, "An irreversible heat engine model including three typical thermodynamic cycles and their optimum performance analysis" International Journal of Thermal Sciences, 2007, 46, 605-613, DOI:10.1016/j.ijthermalsci.2006.04.00.

21. E. Dobrucali, "The effects of the engine design and running parameters on the performance of a Otto-Miller Cycle engine",. Energy, 2016, 103, 119-126, DOI:10.1016/j.energy.2016.02.160.

22. G. Gonca, B. Sahin, and Y. Ust, "Performance maps for an air-standard irreversible Dual-Miller cycle (DMC) with late inlet valve closing (LIVC) version" Energy 2013, 54 ,

285-290,

DOI:10.1016/j.energy.2013.02.004.

23. G. Gonca, and B. Sahin, "The influences of the engine design and operating parameters on the performance of a turbocharged and steam injected diesel engine running with the Miller cycle", Applied Mathematical Modelling, 2016, 40, 3764-3782, DOI:10.1016/j.apm.2015.10.044.

24. G. Gonca, and E. Dobrucali, "Theoretical and experimental study on the performance of a diesel engine fueled with diesel-biodiesel blends", Renewable Energy, 2016, 93, 658-666, DOI:10.1016/j.renene.2016.03.037.

25. G. Gonca, "Effects of engine design and operating parameters on the performance of a spark ignition (SI) engine with steam injection method (SIM)", Applied Mathematical Modelling, 2017, 44, 655-675, DOI:10.1016/j.apm.2017.02.010.

26. A.C. Hernández, J.M.M. Roco, A. Medina and S. Velasco, "An irreversible and optimized four stroke cycle model for automotive engines", European Journal of Physics, 1996, 17, 11.

27. Mousapour, A. Hajipour, Rashidi, and N. Freidoonimehr, "Performance evaluation of an irreversible Miller cycle comparing FTT (finite-time thermodynamics) analysis and 
ANN (artificial neural network) prediction", Energy, 2016, 94, 100-109, DOI:10.1016/j.energy.2015.10.073.

28. Y. Ge, L. Chen and X. Qin, "Effect of specific heat variations on irreversible Otto cycle performance", International Journal of Heat and Mass Transfer, 2018, 122, 403-409, DOI:10.1016/j.ijheatmasstransfer.2018.01.132. 